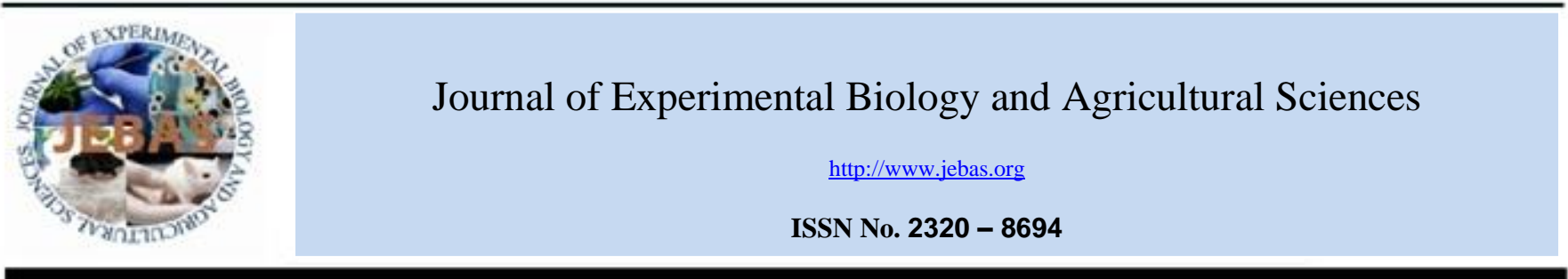

\title{
SELECTION INDEX AS WEIGHTED AVERAGE OF ABSOLUTE SCORES OF AMMI MODEL \& YIELD OF WHEAT GENOTYPES EVALUATED IN NORTH WESTERN PLAINS ZONE OF THE COUNTRY
}

\author{
Ajay Verma*, GP Singh
}

ICAR-Indian Institute of Wheat \& Barley Research, Karnal 132001 Haryana

Received - September 21, 2020; Revision - November 16, 2020; Accepted - December 24, 2020

Available Online - December 30, 2020

DOI: http://dx.doi.org/10.18006/2020.8(6).828.838

KEYWORDS
AMMI analysis
ASV
ZIPC
EV
SI
SSI
Biplot graphs

\begin{abstract}
Highly significant effects of the environment (E), GxE interaction and genotypes (G) observed by AMMI analysis during 2018-19 and 2019-20 study years. First year of the study observed suitability of WH1124\&HD3059 wheat genotypes by WAASB measure. Superiority index while weighting 0.65 and 0.35 for yield \& stability found WH1124 \&PBW771 as of stable performance with high yield. Moreover the average yield of genotypes ranked PBW771 \& WH 1124 as of the order of choice. PRVG and MHPRVG measures observed the suitability of PBW 771 \& PBW752 wheat genotypes. The first two PCAs explained $82.3 \%$ of the variation of the original variables. SI clubbed with EV \& SPIC. Values of SI for wheat genotypes expressed high direct relation with yield, MHPRVG\&PRVG measures only, and negative correlation with remaining measures. WAASB measure exhibited direct relationships with most of the AMMI based stability measures and negative values of correlation with SI, PRVG, MHPRVG and yield. Second year of study wheat genotypes DBW291, WH1264 \& HD3334 were selected by WAASB measure. Superiority index found PBW812, HD3334\& WH1264 as of stable performance along with high yield. MHPRVG measures observed suitability of PBW812, PBW771 \& DBW173 while PRVG favoured PBW812, PBW771\& JKW261 while consensus observed regarding WH1021 \& WH1124 as unstable wheat genotypes. Moreover the average yield of genotypes ranked PBW812, JKW261 \& PBW771 as of the order of choice. Values of SI measure had expressed positive correlation of high magnitude with yield, PRVG and MHPRVG whereas indirect relations of high degree with AMMI based stability measures. Values of WAASB measure had positive relations with AMMI based stability measures along with negative values of correlation with SI, yield, PRVG, and MHPRVG.
\end{abstract}

* Corresponding author

E-mail: 0184-2209149; 01812267390; ajay.verma1@icar.gov.in (Ajay Verma)

\#These authors contributed equally and should be considered as co-first authors

Peer review under responsibility of Journal of Experimental Biology and Agricultural Sciences.

Production and Hosting by Horizon Publisher India [HPI] (http://www.horizonpublisherindia.in/).

All rights reserved.
All the articles published by Journal of Experimental Biology and Agricultural Sciences are licensed under a Creative Commons Attribution-NonCommercial 4.0 International License Based on a work at www.jebas.org.

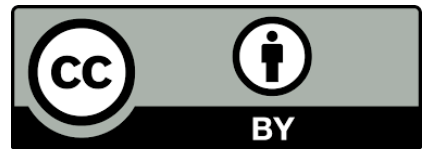




\section{Introduction}

Multilocational yield trials have been conducted worldwide to select highly productive and stable genotypes as the number of genotypes exposed to various environmental conditions simultaneously (Veenstra et al., 2019). Most of the programs developed with the high-yielding widely adapted genotype (Bocianowski et al., 2019). AMMI analysis addresses these challenges of genotype, environment and interaction effects efficiently (Zhang, 1988; Bornhofen et al., 2017). AMMI stability parameters permit to evaluate yield stability after reduction of the noise from the GxE interaction effects (Gauch, 2013; Ajay et al., 2019). Several stability measures as per the AMMI model are available in the literature to estimate the yield stability of genotypes. Only stability is not a desirable selection criterion as stable genotypes may not express high yield, the simultaneous consideration of yield and stability in a single measure had advocated (Kang, 1993; Farshadfar, 2008). Simultaneous Selection Indices had advocated by adding the ranks of stability measure and yields (Farshadfar et al 2011). The quantitative stability measure i.e. Weighted Average of Absolute scores (WAASB), as an important statistical tool recommended for identifying productive genotypes with broad adaptation (Olivoto, 2018). The most stable genotype possessed the lower value of WAASB measure i.e. deviates minimum from the mean performance across environments (Olivoto, 2019). The selection of promising genotypes had been assisted by use of superiority index (WAASBY) that is the simultaneous use of yield and stability by variable weighting mechanism for yield and stability of genotypes (Olivoto et al., 2019). The present study was planned to validate the type of relationships between WAASBY and other stability measures.

\section{Materials and Methods}

States of Punjab, Haryana, Delhi, Rajasthan (except Kota and Udaipur divisions), Western Uttar Pradesh (except Jhansi division and hilly areas), parts of Jammu and Kashmir (Jammu and Kathua districts) and parts of Himachal Pradesh (Paonta Valley and Una districts) comprised the NWPZ of India. Higher Productivity of wheat genotypes had been reported by the states from this mega zone of the country. The major portion of the national buffer stock of cereal cater by this zone. Fifteen major locations of the zone were considered for evaluation of six wheat genotypes and eighteen locations were marked for field evaluation of seventeen genotypes 2018-19 and 2019-20 cropping seasons respectively. Genotypes were replicated for field evaluation by using a random block design. Details of genotype parentage along with environmental conditions were reflected in tables 1 \& 2 for ready reference. Stability measure Weighted Average of Absolute Scores has been calculated as

$\mathrm{WAASB}=\sum_{k=1}^{p}\left|I P C A_{i k} \times E P_{k}\right| / \sum_{k=1}^{p} E P_{k}$

Table 1: Parentage details of genotypes and environmental conditions (2018-19)

\begin{tabular}{|ccccccc|}
\hline Code & Genotype & Parentage & Environments & Latitude & Longitude & Altitude \\
\hline G 1 & PBW 752 & (PBW621/4/PBW343//YR10/6*AVOCET/3/3*PBW343/5/PBW621) & Delhi & $28^{\circ} 4^{\prime} \mathrm{N}$ & $77^{\circ} 13^{\prime} \mathrm{E}$ & 228 \\
\hline G 2 & DBW 173 & (KAUZ/AA//KAUZ/PBW602) & Bawal & $28^{\circ} 10^{\prime} \mathrm{N}$ & $76^{\circ} 50^{\prime} \mathrm{E}$ & 266 \\
\hline G 3 & WH 1021 & (NYOT95/SONAK) & Hisar & $29^{\circ} 10^{\prime} \mathrm{N}$ & $75^{\circ} 46^{\prime} \mathrm{E}$ & 229 \\
\hline G 4 & HD 3059 & (KAUZ//ALTAR84/AOS/3/MILAN/KAUZ/4/HUITES) & Karnal & $29^{\circ} 43^{\prime} \mathrm{N}$ & $70^{\circ} 58^{\prime} \mathrm{E}$ & 245 \\
\hline G 5 & WH 1124 & (MUNIA/CHTO//AMSEL) & Rohtak & $28^{\circ} 53^{\prime} \mathrm{N}$ & $76^{\circ} 35^{\prime} \mathrm{E}$ & 222.5 \\
\hline G 6 & PBW 771 & (PBW550//YR15/6*AVOCET/3/2*PBW550) & Shikohpur & & \\
\hline & & Jammu & $32^{\circ} 40^{\prime} \mathrm{N}$ & $74^{\circ} 54^{\prime} \mathrm{E}$ & 356 \\
\hline & & Ludhiana & $30^{\circ} 54^{\prime} \mathrm{N}$ & $75^{\circ} 48^{\prime} \mathrm{E}$ & 247 \\
\hline & & Kapurthala & $31^{\circ} 22^{\prime} \mathrm{N}$ & $75^{\circ} 22^{\prime} \mathrm{E}$ & 229 \\
\hline & & Gurdaspur & $30^{\circ} 02^{\prime} \mathrm{N}$ & $75^{\circ} 24^{\prime} \mathrm{E}$ & 265 \\
\hline & & Bathinda & $30^{\circ} 09^{\prime} \mathrm{N}$ & $74^{\circ} 55^{\prime} \mathrm{E}$ & 211 \\
\hline & & Faridkot & $30^{\circ} 40^{\prime} \mathrm{N}$ & $74^{\circ} 04^{\prime} \mathrm{E}$ & 200 \\
\hline & & Durgapura & $26^{\circ} 51^{\prime} \mathrm{N}$ & $75^{\circ} 47^{\prime} \mathrm{E}$ & 390 \\
\hline & & Tabiji & $26^{\circ} 35^{\prime} \mathrm{N}$ & $74^{\circ} 61^{\prime} \mathrm{E}$ & 508 \\
\hline & & Sriganganagar & $29^{\circ} 66^{\prime} \mathrm{N}$ & $75^{\circ} 53^{\prime} \mathrm{E}$ & 175.6 \\
\hline & & Alwar & $27^{\circ} 7{ }^{\prime} \mathrm{N}$ & $76^{\circ} 1{ }^{\prime} \mathrm{E}$ & 271 \\
\hline & & Nagina & $29^{\circ} 28^{\prime} \mathrm{N}$ & $78^{\circ} 32^{\prime} \mathrm{E}$ & 245 \\
\hline & Bulandshahr & $28^{\circ} 40^{\prime} \mathrm{N}$ & $77^{\circ} 84^{\prime} \mathrm{E}$ & 195 \\
\hline & Ujhani & Pantnagar & $29^{\circ} 02^{\prime} \mathrm{N}$ & $79^{\circ} 48^{\prime} \mathrm{E}$ & 243.8 \\
\hline & Kashipur & $29^{\circ} 21^{\prime} \mathrm{N}$ & $78^{\circ} 96^{\prime} \mathrm{E}$ & 218 \\
\hline
\end{tabular}

Journal of Experimental Biology and Agricultural Sciences http://www.jebas.org 


\begin{tabular}{|c|c|c|c|c|c|c|}
\hline \multicolumn{5}{|l|}{830} & \multicolumn{2}{|c|}{ Verma \& Singh } \\
\hline Code & Genotype & Parentage & Environments & Latitude & Longitude & Altitude \\
\hline G 1 & HD3334 & (DBW 50/WR2502) & Delhi & $28^{\circ} 4^{\prime} \mathrm{N}$ & $77^{\circ} 13^{\prime} \mathrm{E}$ & 228 \\
\hline G 2 & HD3059 & (KAUZ//ALTAR84/AOS/3/MILAN/KAUZ/4/HUITES) & Hisar & $29^{\circ} 10^{\prime} \mathrm{N}$ & $75^{\circ} 46^{\prime} \mathrm{E}$ & 229 \\
\hline G 3 & HD3332 & (PFAU/SERI.1B) & Karnal & $29^{\circ} 43^{\prime} \mathrm{N}$ & $70^{\circ} 58^{\prime} \mathrm{E}$ & 245 \\
\hline G 4 & DBW173 & (KAUZ/AA//KAUZ//PBW602) & Rohtak & $28^{\circ} 53^{\prime} \mathrm{N}$ & $76^{\circ} 35^{\prime} \mathrm{E}$ & 222.5 \\
\hline G 5 & WH1021 & (NYOT95/SONAK) & Shikohpur & & & \\
\hline G 6 & PBW811 & $(\mathrm{BECARD} / 2 * \mathrm{FRNCLN})$ & Ludhiana & $30^{\circ} 54^{\prime} \mathrm{N}$ & $75^{\circ} 48^{\prime} \mathrm{E}$ & 247 \\
\hline G 7 & DBW291 & (KRL236/DBW16) & Kapurthala & $31^{\circ} 22^{\prime} \mathrm{N}$ & $75^{\circ} 22^{\prime} \mathrm{E}$ & 229 \\
\hline G 8 & WH1264 & (P12256/P12332//WH1142) & Gurdaspur & $30^{\circ} 02^{\prime} \mathrm{N}$ & $75^{\circ} 24^{\prime} \mathrm{E}$ & 265 \\
\hline G 9 & PBW812 & (BWL 0762/PBW621//HD 3086) & Bathinda & $30^{\circ} 09^{\prime} \mathrm{N}$ & $74^{\circ} 55^{\prime} \mathrm{E}$ & 211 \\
\hline G 10 & JKW261 & (ISENGRAIN/KBIRD//MUNAL\#1) & Faridkot & $30^{\circ} 40^{\prime} \mathrm{N}$ & $74^{\circ} 04^{\prime} \mathrm{E}$ & 200 \\
\hline G 11 & DBW290 & $\begin{array}{c}\text { (QUAIU\#1/5/KIRITATI/4/2*SERI.1B*2/3/KAUZ*2/BOW// } \\
\text { KAUZ/6/BECARD(35th ESWYT 140) }\end{array}$ & Durgapura & $26^{\circ} 51^{\prime} \mathrm{N}$ & $75^{\circ} 47^{\prime} \mathrm{E}$ & 390 \\
\hline G 12 & PBW771 & (PBW550//YR15/6*AVOCET/3/2*PBW550) & Sriganganagar & $29^{\circ} 66^{\prime} \mathrm{N}$ & $75^{\circ} 53^{\prime} \mathrm{E}$ & 175.6 \\
\hline G 13 & PBW813 & $\begin{array}{c}\text { (KRICHAUFF/4/2*BW9250*3//Yr10/6*Avocet/3/BW } \\
9250 * 3 / / \text { Yr 15/6*Avocet }\end{array}$ & Nagina & $29^{\circ} 28^{\prime} \mathrm{N}$ & $78^{\circ} 32^{\prime} \mathrm{E}$ & 245 \\
\hline G 14 & HD3331 & (31stESWYT-135/3/HD2329/WR544//PBW343/NW3041) & Bulandshahr & $28^{\circ} 40^{\prime} \mathrm{N}$ & $77^{\circ} 84^{\prime} \mathrm{E}$ & 195 \\
\hline G 15 & HD3298 & (CL1449/PBW343//CL882/HD2009) & Ujhani & & & \\
\hline G 16 & WH1124 & (MUNIA/CHTO//AMSEL) & Modipuram & & & \\
\hline G 17 & UP3033 & (NIAW 1544/UP2763) & Pantnagar & $29^{\circ} 02^{\prime} \mathrm{N}$ & $79^{\circ} 48^{\prime} \mathrm{E}$ & 243.8 \\
\hline & & & Kashipur & $29^{\circ} 21^{\prime} \mathrm{N}$ & $78^{\circ} 96^{\prime} \mathrm{E}$ & 218 \\
\hline
\end{tabular}

Where $\mathrm{WAASB}_{\mathrm{i}}$ is the weighted average of absolute scores of the $i^{\text {th }}$ genotype (or environment); $\operatorname{IPCA}_{i k}$ is the score of the $i^{\text {th }}$ genotype (or environment) in the $k^{\text {th }}$ IPCA, and $\mathrm{EP}_{k}$ is the amount of the variance explained by the $k^{\text {th }}$ IPCA. Superiority index has been put forward that allows weighting between yield and stability measure (WAASB) to select genotypes that combine high yield and stability as

$\mathrm{SI}=\frac{\left(r G_{i} \times \theta_{Y}\right)+\left(r W_{i} \times \theta_{S}\right)}{\left(\theta_{Y}+\theta_{S}\right)}$

where $r G_{i}$ and $r W_{i}$ are the rescaled values for yield and WAASB, respectively, for the $i^{\text {th }}$ genotype; $G_{i}$ and $W_{i}$ are the yield and the WAASB values for $i^{\text {th }}$ genotype. SI superiority index for the $i^{\text {th }}$ genotype that weights between yield and stability, and $\theta Y$ and $\theta S$ are the weights for yield and stability assumed to be of order 65 and 35 respectively in this study,

$\begin{aligned} & \text { Zobel et al., } \\ & 1982 \quad \begin{array}{c}\text { Averages of the } \\ \text { squared eigenvector } \\ \text { values }\end{array}\end{aligned} \mathrm{EV}=\sum_{n=1}^{N} \lambda_{i n}^{2} / n$
Sneller et Sums of the absolute al., 1997

Purchase et al., 2000

Rao \& Prabhakara n 2005

Zali et al., 2012

Zali et al. 2012

Zali et al., 2012

AMMI stability Value

AMMI based stability parameter

ASV1 stability Value

Absolute value of the relative contribution
Sums of the absolute
value of the IPC
scores SIPC $=\sum_{n=1}^{N} \lambda_{n}^{0.5} \gamma_{\text {in }}$

$\mathrm{ASV}=\left[\left(\frac{\operatorname{SSIPC} 1}{\operatorname{SSIPC} 2} P C I\right)^{2}+(P C 2)^{2}\right]^{1 / 2}$

$A S T A B=\sum_{n=1}^{n} \lambda_{n} \gamma_{n i}^{2}$ $\mathrm{ASV} 1=\left[\frac{\operatorname{SSIPC} 1}{\operatorname{SSIPC} 2}(P C I)^{2}+(P C 2)^{2}\right]^{1 / 2}$

Modified AMMI $M A S V=$ $\sqrt{\sum_{n=1}^{N-1} \frac{\operatorname{SSIPC}_{n}}{\operatorname{SSIPC}_{n+1}}\left(P C_{n}\right)^{2}+\left(P C_{n+1}\right)^{2}}$

$$
\mathrm{Z}_{\mathrm{a}}=\sum_{n=1}^{N}\left|\lambda_{n} \gamma_{i n}\right|
$$
of IPCs to the interaction 


\begin{tabular}{|c|c|c|}
\hline Ajay et al., & MASV1 & MASV1 = \\
\hline & & $\sqrt{\sum_{n=1}^{N-1}\left(\frac{\operatorname{SSIPC}_{n}}{\operatorname{SSIPC}_{n+1}} P C_{n}\right)^{2}+\left(P C_{n+1}\right)^{2}}$ \\
\hline $\begin{array}{l}\text { Resende \& } \\
\text { Durate } \\
2007\end{array}$ & $\begin{array}{c}\text { Relative } \\
\text { performance of } \\
\text { genotypic values } \\
\text { across environments }\end{array}$ & $\mathrm{PRVG}_{\mathrm{ij}}=\mathrm{VG}_{\mathrm{ij}} / \mathrm{VG}_{\mathrm{i}}$ \\
\hline $\begin{array}{l}\text { Resende \& } \\
\text { Durate }\end{array}$ & $\begin{array}{l}\text { Harmonic mean of } \\
\text { Relative }\end{array}$ & MHPRVG $_{\mathrm{i}}=$ \\
\hline 2007 & $\begin{array}{l}\text { performance of } \\
\text { genotypic values }\end{array}$ & $\sum_{j=1}^{k} \frac{1}{P R V G_{i j}}$ \\
\hline $\begin{array}{l}\text { Olivato et } \\
\text { al., } 2019\end{array}$ & Superiority Index & $\mathrm{SI}=\frac{\left(r G_{i} \times \theta_{Y}\right)+\left(r W_{i} \times \theta_{S}\right)}{\left(\theta_{Y}+\theta_{S}\right)}$ \\
\hline
\end{tabular}

AMMI analysis was performed using AMMISOFT version 1.0, available at https://scs.cals.cornell.edu/people/ hugh-gauch/and SAS software version 9.3. Analytic measures of adaptability (Resende \& Durate, 2007) were also calculated and compared with the Superiority Index

\section{Results and Discussion}

\subsection{First year (2018-19)}

\subsubsection{AMMI analysis}

AMMI based stability measures permit to evaluate the stability of genotypes after reduction of the noise from the GxE interaction effects. Highly significant effects of the environment (E), GxE interaction and genotypes (G) were observed (Table 3). Environment explained about $42.8 \%$ of the total sum of squares due to treatments. Moreover up to $80 \%$ contribution of environmental effects reported in various crops (Oyekunle et al., 2017). Genotypes explained only $15.6 \%$ of the total sum of squares, whereas GxE interaction accounted for $24.6 \%$ of treatment variations in yield. Higher GxE interaction sum of squares as compared to genotypes indicated the presence of genotypic differences across environments and complex GxE interaction for wheat yield. GxE interaction was further divided into four significant multiplicative terms (IPCA1, IPCA2, IPCA3, and IPCA4) with corresponding 53.6\%, 20.4\%, 13.8\%, and $9.3 \%$ of interaction sum of squares, respectively. The total of significant components was $97 \%$ and the remaining $2.8 \%$ is the residual or noise, which is not interpretable and thus discarded (Adjebeng et al., 2017).

\subsubsection{Stability measures of wheat genotypes}

Least value of absolute IPCA1 is expressed by G5, G1and the higher value is achieved by G3 (Table 5). Low values of (EV) associated with stable genotype accordingly, the genotype G2 followed by G3 and genotype G6 had the maximum value of EV measure. The lower value SIPC measure identified G2 followed by G4 whereas G6 would be of least stable behaviour. Measure Za based on absolute value of the relative contribution of IPCs to the interaction revealed G4, G5 as most stable genotypes in descending order of stability, whereas G3 genotype with the least stability. ASV measure showed that genotypes G4, G5 possessed lower values would express stable performance and G3 be of least stable type. Values of ASV1 selected G4, G5 for their stable behaviour whereas G3 would express unstable performance.

Table 3: AMMI analysis of wheat genotypes evaluated under MET (2018-19)

\begin{tabular}{|c|c|c|c|c|c|c|}
\hline Source & $\begin{array}{l}\text { Degree of } \\
\text { freedom }\end{array}$ & $\begin{array}{l}\text { Mean Sum } \\
\text { of Squares }\end{array}$ & $\begin{array}{l}\text { Level of } \\
\text { significance }\end{array}$ & $\begin{array}{l}\% \text { contribution of } \\
\text { factors }\end{array}$ & $\begin{array}{c}\text { GxE interaction } \\
\text { Sum of Squares }(\%)\end{array}$ & $\begin{array}{c}\text { Cumulative Sum of Squares } \\
(\%) \text { by IPCA's }\end{array}$ \\
\hline Treatments & 125 & 250.56 & $* * *$ & 83.00 & & \\
\hline Genotype (G) & 5 & 1178.31 & $* * *$ & 15.61 & & \\
\hline $\begin{array}{l}\text { Environment } \\
\text { ( E ) }\end{array}$ & 20 & 808.31 & $* * *$ & 42.84 & & \\
\hline GxE interaction & 100 & 92.63 & $* * *$ & 24.55 & & \\
\hline IPC1 & 24 & 206.89 & $* * *$ & & 53.60 & 53.60 \\
\hline IPC2 & 22 & 86.01 & $* * *$ & & 20.43 & 74.03 \\
\hline IPC3 & 20 & 63.69 & $* * *$ & & 13.75 & 87.78 \\
\hline IPC4 & 18 & 47.51 & $* *$ & & 9.23 & 97.02 \\
\hline Residual & 16 & 17.28 & 0.43 & & & \\
\hline Error & 378 & 16.97 & & & & \\
\hline Total & 503 & 75.02 & & & & \\
\hline
\end{tabular}

Journal of Experimental Biology and Agricultural Sciences http://www.jebas.org 
Measures MASV and MASV1consider all significant IPCAs. Values of MASV showed that the genotypes, G6 and G5 were most stable and G5 \& G6 would be stable by MASV1measure respectively (Ajay et al 2019). ASTAB measure observed genotypes G5 and G12 as most stable and genotype G1 was least stable in this study (Rao \& Prabhakaran 2005). The lower values of WAASB associated with stable nature of genotypes as G5, G4 expressed lower values and would stable genotypes for considered locations of the zone at the same time maximum value obtained by $\mathrm{G} 3$, that is, the one that deviates maximum from the average performance across environments (Olivato, 2018). The lower value of Superiority index had observed for G3 and G4 whereas large value by G6. Adaptability measures MHPRVG and PRVG identified G3 and G4 wheat genotypes for higher stable yield performance (Resende \& Durate, 2007). Maximum yield expressed by G6 followed by G5 and G1 as little variation observed from 51.1 to $40.9 \mathrm{q} / \mathrm{ha}$ among genotypes.

\subsubsection{Ranking of Genotypes as per AMMI measures and Yield}

The wheat genotypes were then ranked based on SSI for each of the twelve measures of stability from the AMMI model such that genotype with high yield and stability gets top rank, whereas lowyielding and unstable genotype gets the least rank. The SSI rank orders displayed by these measures of stability from the AMMI model are presented in Table 7. As per the least values of simultaneous ranks for IPCA1 measure WH1124\&PBW771 were considered as stable with high yield, whereas high values suggested as the least stable yield for WH1021 genotype. EV measure identified WH 1124 \& DBW173 whereas SPIC favoured DBW173 \&PBW752 genotypes. WH1124 \&PBW752 genotypes possessed a lower value of $\mathrm{Za}$ measure. Composite measures MASV selected PBW771, WH 1124, and MASV1 as WH1124, PBW771 genotypes of choice for these locations of the zone. Values of the least magnitude of ASV and ASV1 pointed towards WH1124 and PBW771 wheat genotypes. In the present study, all measures identified genotypes WH1124 and PBW771as stable and high yielders. WAASB measure observed suitability of WH1124 \& HD3059 genotypes. Superiority index while weighting 0.65 and 0.35 for yield \& stability found WH1124 \& PBW771 as of stable performance with high yield. PRVG and MHPRVG measures observed the suitability of PBW 771 \& PBW752 wheat genotypes. Moreover the average yield of genotypes ranked PBW771 \& WH 1124 as of the order of choice.

\subsubsection{Biplot analysis of stability measures}

Biplot graphical analysis based on two significant principal component analysis (PCA) by considering the simultaneous ranks of wheat genotypes evaluated under multi environment trials (Figure 1). Loadings of stability measures for wheat genotypes are reflected in table 9. The first two PCAs explained $82.3 \%$ of the variation of the original variables (Balestre et al., 2009). The PC1 and PC2 axes distinguish stability measures into three groups. SI clubbed with EV \& SPIC and Yield clustered with MASV, PRVG \& MHPRVG measures. The large group comprises of yield with ASTAB, ASV, IPCA1, ASV1, MASV1, and Za measures. WAASB measure maintained a distance from all stability measures as observed as an outlier in graphical presentation. This showed the stability performance of genotypes differed as compared to other measures.

\subsubsection{Association analysis of stability measures}

Karl Pearson Correlation coefficient values were computed for each pair of measures to have an idea of association analysis among measures. Mean yield showed only significant positive correlations with SI and relative yield based MHPRVG \& PRVG measures (Table 11). While other measures expressed only negative values MASV1, MASV, ASTAB, IPCA1, ASV1, ASV, WAASB measures. Values of SI for wheat genotypes expressed high direct relation with yield, MHPRVG \& PRVG measures only and negative correlation with remaining measures. WAASB measure exhibited direct relationships with most of the AMMI based stability measures and negative values of correlation with SI, PRVG, MHPRVG and yield. AMMI based measures Za, ASV, ASV1, MASV1, MASV, and ASTAB achieved only positive correlation values among themselves as well as with other stability measures. ASTAB had an indirect relation with SI, PRVG, MHPRVG, and yield. Positive correlations of low magnitude exhibited by SIPC measures with SI, PRVG, MHPRVG, and yield. Indirect relations of Za measures observed for SI, PRVG, MHPRVG and yield. This behaviour of negative correlations had also displayed by IPCA1, ASV1, MASV1, ASV, MASV measures. Selection of more stable yield performing wheat genotypes as per AMMI based measures would not be the same as identified by Superiority Index.

\subsection{Second year (2019-20)}

\subsubsection{AMMI analysis}

AMMI analysis observed highly significant effects of the environment (E), GxE interaction and genotypes (G). Diversity of environmental effects is judged by $39.2 \%$ of the total sum of squares due to treatments explained by environments only (Table 4). Genotypes explained $11.8 \%$ of the total sum of squares, whereas GxE interaction explained 35.6\% of treatment variation in yield. Partitioning of GxE interaction revealed that IPCA1, IPCA2, ... IPCA7) of AMMI were significant and explained $31.9 \%, 17.6 \% 11.6 \%, 9.5 \%, 8.8 \%, 4.8 \%$ and $4.3 \%$ of $\mathrm{GxE}$ interaction sum of squares, respectively. Approximately $88.7 \%$ of the sum of squares accounted by seven PC's and little left the residual or noise was discarded. AMMI based measures by utilizing only seven significant interaction principal components would be sufficient for the decision taken. 
Table 4: AMMI analysis of wheat genotypes evaluated under MET (2019-20)

\begin{tabular}{|c|c|c|c|c|c|c|}
\hline Source & $\begin{array}{l}\text { Degree of } \\
\text { freedom }\end{array}$ & $\begin{array}{l}\text { Mean Sum of } \\
\text { Squares }\end{array}$ & $\begin{array}{c}\text { Level of } \\
\text { significance }\end{array}$ & $\begin{array}{c}\% \\
\text { contribution } \\
\text { of factors }\end{array}$ & $\begin{array}{c}\text { GxE interaction } \\
\text { Sum of Squares (\%) }\end{array}$ & $\begin{array}{c}\text { Cumulative Sum of Squares } \\
(\%) \text { by IPCA's }\end{array}$ \\
\hline Treatments & 305 & 214.92 & $* * *$ & 86.58 & & \\
\hline Genotype (G) & 16 & 556.53 & $* * *$ & 11.76 & & \\
\hline $\begin{array}{l}\text { Environment } \\
(\mathrm{E})\end{array}$ & 17 & 1744.59 & $* * *$ & 39.17 & & \\
\hline GxE interaction & 272 & 99.22 & $* * *$ & 35.64 & & \\
\hline IPC1 & 32 & 269.40 & $* * *$ & & 31.94 & 31.94 \\
\hline IPC2 & 30 & 158.63 & $* * *$ & & 17.63 & 49.58 \\
\hline IPC3 & 28 & 111.87 & $* * *$ & & 11.61 & 61.18 \\
\hline IPC4 & 26 & 99.02 & $* * *$ & & 9.54 & 70.72 \\
\hline IPC5 & 24 & 98.97 & $* * *$ & & 8.80 & 79.52 \\
\hline IPC6 & 22 & 59.39 & $* * *$ & & 4.84 & 84.37 \\
\hline IPC7 & 20 & 57.93 & $* * *$ & & 4.29 & 88.66 \\
\hline Residua & 90 & 34.01 & $* * *$ & & & \\
\hline Error & 918 & 11.07 & & & & \\
\hline Total & 1223 & 61.91 & & & & \\
\hline
\end{tabular}

Table 5: Measures of stability as per AMMI analysis (2018-19)

\begin{tabular}{|c|c|c|c|c|c|c|c|c|c|c|c|c|c|c|}
\hline & IPCA1 & MASV1 & MASV & ASV1 & ASV & $\mathrm{Za}$ & $\mathrm{EV}$ & SIPC & ASTAB & WAASB & SI & MHPRVG & PRVG & Yield \\
\hline G 1 & 0.34 & 7.31 & 6.41 & 4.09 & 4.03 & 17.21 & 0.096 & 5.22 & 108.98 & 1.16 & 88.64 & 1.0437 & 1.0508 & 49.82 \\
\hline G 2 & 2.95 & 7.79 & 4.86 & 7.73 & 4.78 & 20.64 & 0.037 & 4.06 & 77.02 & 1.66 & 65.53 & 0.9963 & 1.0040 & 47.85 \\
\hline G 3 & 4.87 & 12.83 & 7.95 & 12.79 & 7.91 & 32.89 & 0.087 & 6.02 & 202.11 & 2.69 & 0.00 & 0.8441 & 0.8640 & 40.95 \\
\hline G 4 & 0.72 & 6.68 & 5.76 & 2.00 & 1.33 & 16.16 & 0.091 & 5.07 & 80.99 & 1.08 & 63.46 & 0.9551 & 0.9606 & 45.65 \\
\hline G 5 & 0.05 & 5.38 & 4.84 & 2.00 & 1.99 & 16.43 & 0.087 & 6.09 & 72.56 & 1.00 & 91.86 & 1.0418 & 1.0462 & 49.83 \\
\hline G 6 & 1.49 & 5.68 & 4.59 & 4.04 & 2.62 & 22.09 & 0.102 & 6.72 & 83.24 & 1.52 & 89.22 & 1.0686 & 1.0744 & 51.10 \\
\hline
\end{tabular}

\subsection{Stability measures of wheat genotypes}

Least value of absolute IPCA1 is expressed by G14, G3, G1, and the higher value is achieved by G5 (Table 6). Stable performance of G7, G8, G1 genotypes anticipated as lower values of EV were exhibited by genotypes. The absolute value of the relative contribution of IPCs to the interaction ( $\mathrm{Za}$ ) revealed G7, G8, and G1 genotypes as most stable in descending order of stability, whereas G5 genotype with the least stability. The sums of the absolute value of the IPC scores (SIPC) identified G7 followed by G8 and G1 as the most stable genotypes, whereas G5 as the least stable one. AMMI-based stability parameter (ASTAB) identified genotypes G7, G1, and G8 as most stable and genotype G5 was least stable in this study. Values of ASV measure showed that genotype G1, G2, G12 would show the stable performance and G5 the least stable. ASV1 selected G1, G2, G3 for their stable behaviour whereas G5 would express unstable performance. The values of MASV showed that the genotypes G7, G9, and G1 were the most and MASV1 considered G7, G9, G8 would be genotypes of stable yield and G5 would be least stable by measures. The genotype with the lowest WAASB value is considered the most stable, that is, the one that deviates least from the average performance across environments.G7, G8 \& G1 pointed by measure WAASB as desirable genotypes for considered locations of the zone. Superiority index had observed that genotypes G5, G16, and G3 whereas large value by G9. Stable performance of genotypes G5 G16 G3 assured by values of PRVG measure while MHPRVG measure selected G5, G16, G3 along with least stable yield of G9. Maximum yield expressed by G9 followed by G10 and G12 as good variation observed from 38.2 to $49.4 \mathrm{q} / \mathrm{ha}$ among genotypes. The high yield wheat genotypes as per average yield would not be of stable performance for the considered locations of the zone. 


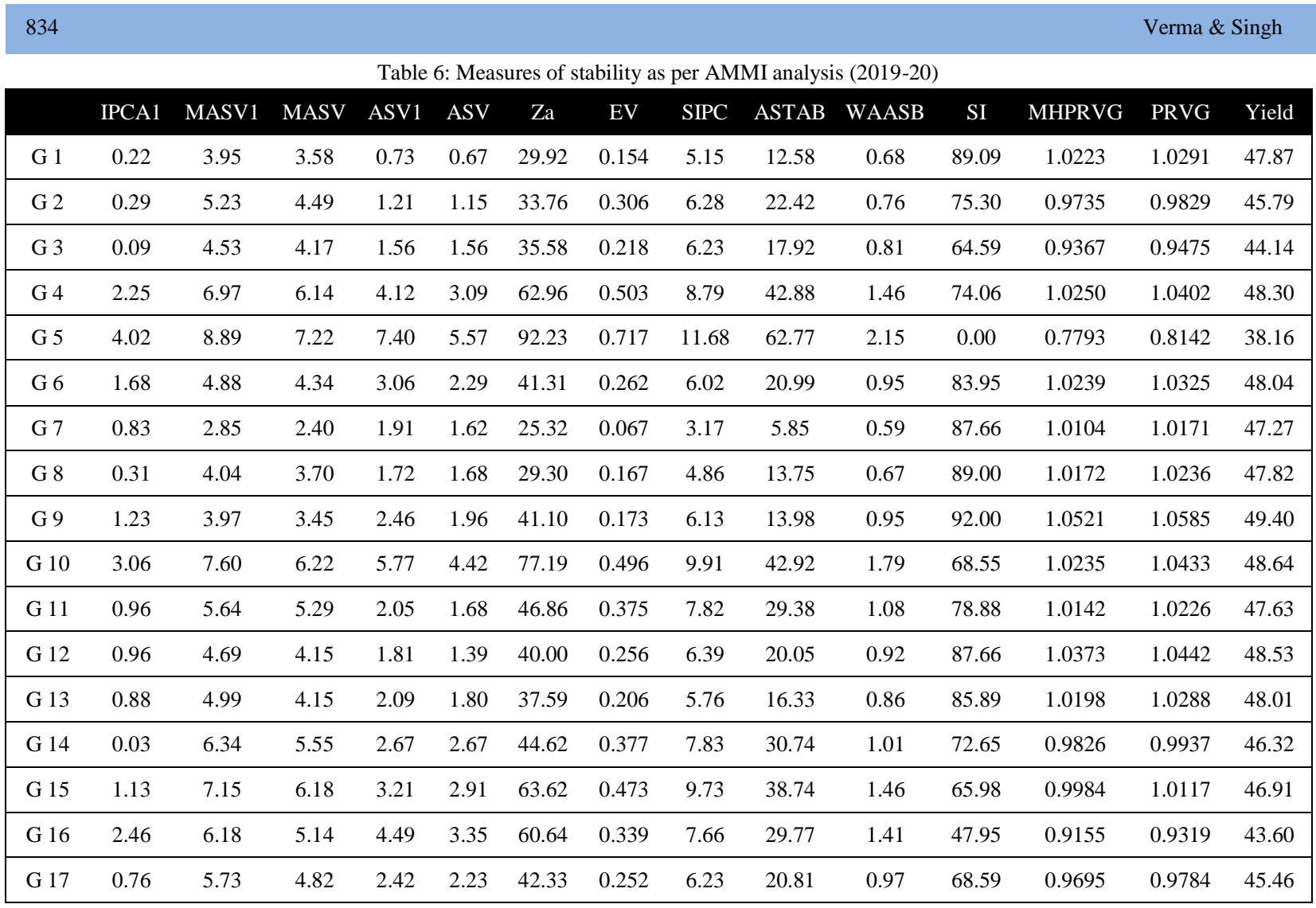

Table 7: Simultaneous ranks of genotypes as per yield and AMMI based measures (2018-19)

\begin{tabular}{|c|c|c|c|c|c|c|c|c|c|c|c|c|c|c|}
\hline Genotype & IPCA1 & MASV1 & MASV & ASV1 & ASV & $\mathrm{Za}$ & EV & SIPC & ASTAB & WAASB & SI & MHPRVG & PRVG & Yield \\
\hline PBW 752 & 5 & 7 & 8 & 7 & 7 & 6 & 8 & 6 & 8 & 3 & 3 & 2 & 2 & 3 \\
\hline DBW 173 & 9 & 9 & 7 & 9 & 9 & 8 & 5 & 5 & 6 & 5 & 4 & 4 & 4 & 4 \\
\hline WH 1021 & 12 & 12 & 12 & 12 & 12 & 12 & 9 & 10 & 12 & 6 & 6 & 6 & 6 & 6 \\
\hline HD 3059 & 8 & 8 & 9 & 7 & 6 & 6 & 9 & 7 & 8 & 2 & 5 & 5 & 5 & 5 \\
\hline WH 1124 & 3 & 3 & 4 & 3 & 4 & 4 & 4 & 7 & 3 & 1 & 1 & 3 & 3 & 2 \\
\hline PBW 771 & 5 & 3 & 2 & 4 & 4 & 6 & 7 & 7 & 5 & 4 & 2 & 1 & 1 & 1 \\
\hline
\end{tabular}

\subsubsection{Ranking of Genotypes as per AMMI measures and Yield}

Least ranks of genotypes as per values of IPCA1 measure considered HD3334, WH1264 \&PBW812genotypes with stable high yield, whereas high values for WH1021 suggested as least stable yield (Table 8). EV measure identified PBW812, HD3334 \& DBW291 for stable performance whereas as per values of SPIC PBW812, HD3334 \& PBW811 were favoured genotypes. PBW812, PBW771 \& HD3334 genotypes possessed a lower value of $\mathrm{Za}$ measure. Least values of ASV and ASV1 pointed towards PBW771, HD3334 and PBW812 wheat genotypes. More or less all measures identified PBW812, PBW771 and HD3334 genotypes for stable and high yield as per considered locations of this zone.
Modified AMMI stability Value measure MASV selected PBW812, PBW771, HD3334 and MASV1 as PBW812, PBW771, HD3334 genotypes of choice for these locations of the zone. AMMI based measures had identified more or less the same set of wheat genotypes.

WAASB measure observed suitability of DBW291, WH1264 \& HD3334 wheat genotypes for the locations of this zone. Superiority index while weighting 0.65 and 0.35 for yield \& stability found PBW812, HD3334 \& WH1264 as of stable performance along with high yield. MHPRVG measures observed suitability of PBW812, PBW771\& DBW173 while PRVG favoured PBW812, PBW771 \& JKW261 while consensus observed regarding WH1021 \& WH1124 as unstable wheat genotypes. Moreover, the average yield of 
Table8 : Simultaneous ranks of genotypes as per yield and AMMI based measures (2019-20)

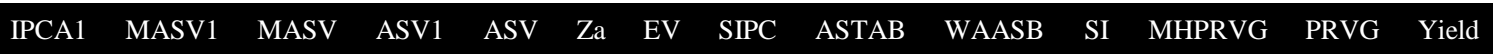

\begin{tabular}{|cccccccccccccccc|}
\hline HD3334 & 10 & 9 & 10 & 8 & 8 & 10 & 9 & 10 & 9 & 3 & 2 & 6 & 6 & 7 \\
\hline HD3059 & 17 & 22 & 22 & 15 & 15 & 17 & 23 & 22 & 23 & 4 & 9 & 13 & 13 & 13 \\
\hline HD3332 & 17 & 20 & 22 & 18 & 19 & 20 & 21 & 22 & 21 & 5 & 15 & 15 & 15 & 15 \\
\hline DBW173 & 18 & 18 & 18 & 18 & 18 & 18 & 20 & 18 & 19 & 14 & 10 & 3 & 4 & 4 \\
\hline WH1021 & 34 & 34 & 34 & 34 & 34 & 34 & 34 & 34 & 34 & 17 & 17 & 17 & 17 & 17 \\
\hline PBW811 & 18 & 12 & 13 & 17 & 16 & 14 & 14 & 10 & 14 & 9 & 7 & 4 & 5 & 5 \\
\hline DBW291 & 17 & 11 & 11 & 16 & 15 & 11 & 11 & 11 & 11 & 1 & 5 & 10 & 10 & 10 \\
\hline WH1264 & 13 & 12 & 12 & 12 & 14 & 10 & 11 & 10 & 11 & 2 & 3 & 8 & 8 & 8 \\
\hline PBW812 & 13 & 4 & 3 & 11 & 10 & 9 & 5 & 7 & 5 & 8 & 1 & 1 & 1 & 1 \\
\hline JKW261 & 18 & 18 & 18 & 18 & 18 & 18 & 17 & 18 & 18 & 16 & 13 & 5 & 3 & 2 \\
\hline DBW290 & 19 & 19 & 21 & 16 & 16 & 21 & 21 & 21 & 20 & 12 & 8 & 9 & 9 & 9 \\
\hline PBW771 & 12 & 9 & 8 & 8 & 6 & 10 & 11 & 13 & 10 & 7 & 4 & 2 & 2 & 3 \\
\hline PBW813 & 14 & 14 & 12 & 14 & 14 & 12 & 11 & 10 & 11 & 6 & 6 & 7 & 7 & 6 \\
\hline HD3331 & 13 & 25 & 25 & 23 & 24 & 23 & 25 & 25 & 25 & 11 & 11 & 12 & 12 & 12 \\
\hline HD3298 & 22 & 26 & 26 & 24 & 24 & 26 & 25 & 26 & 25 & 15 & 14 & 11 & 11 & 11 \\
\hline WH1124 & 31 & 28 & 27 & 31 & 31 & 29 & 27 & 27 & 28 & 13 & 16 & 16 & 16 & 16 \\
\hline UP3033 & 20 & 25 & 24 & 23 & 24 & 24 & 21 & 22 & 22 & 10 & 12 & 14 & 14 & 14 \\
\hline
\end{tabular}

Table 9: Loadings of stability measures as per first two PC's

\begin{tabular}{|ccc|}
\multicolumn{4}{c}{$2018-19$} \\
\hline Measure & PC1 & PC2 \\
\hline IPCA1 & 0.294 & 0.116 \\
\hline MASV1 & 0.298 & 0.023 \\
\hline MASV & 0.284 & -0.209 \\
\hline ASV1 & 0.296 & 0.165 \\
\hline ASV & 0.286 & 0.208 \\
\hline Za & 0.280 & 0.314 \\
\hline EV & 0.191 & -0.073 \\
\hline SIPC & 0.172 & -0.097 \\
\hline ASTAB & 0.284 & 0.047 \\
\hline WAASB & 0.208 & 0.633 \\
\hline SI & 0.295 & -0.070 \\
\hline MHPRVG & 0.261 & -0.375 \\
\hline PRVG & 0.261 & -0.375 \\
\hline Yield & 0.289 & -0.262 \\
\hline$\%$ variance & 76.09 & 9.16 \\
\hline & & \\
\hline
\end{tabular}

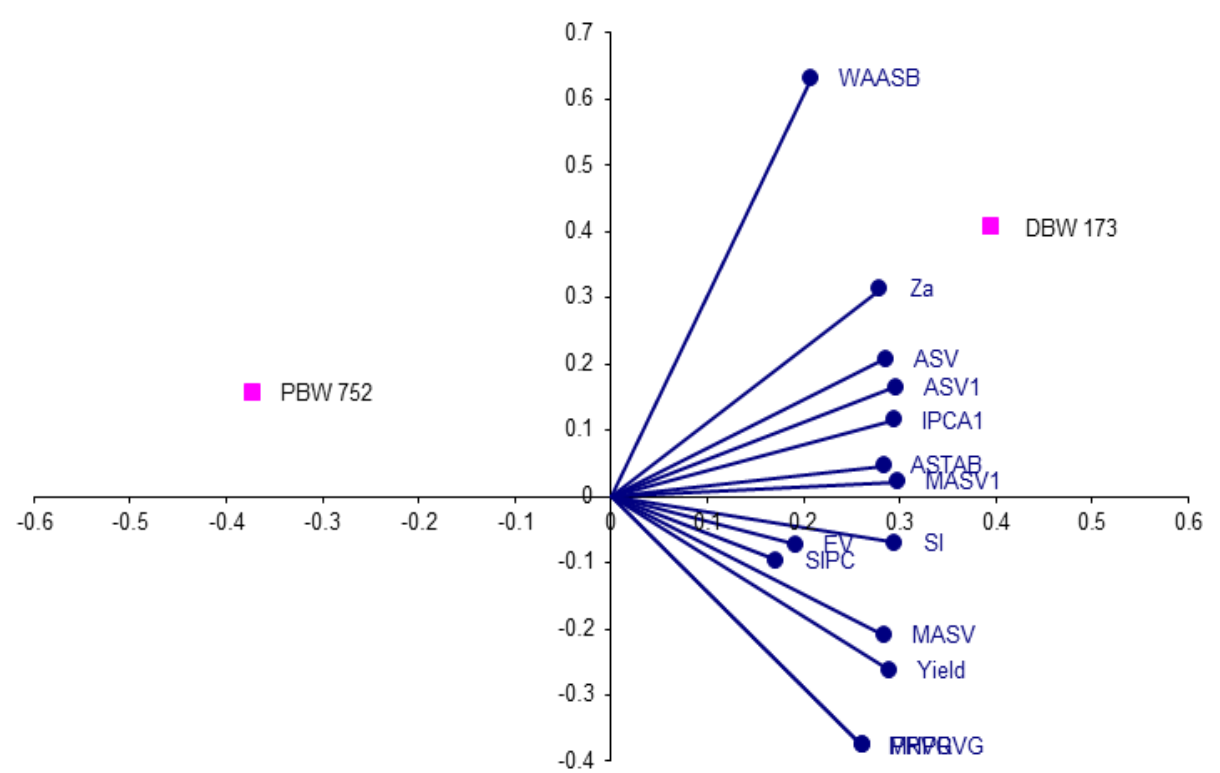

Figure 1: Biplot graphical analysis of stability measures for wheat genotypes evaluated under MET (2018-19 genotypes ranked PBW812, JKW261 \& PBW771 as of the order of choice. Stability of genotypes and stable high performance as judged by WAASB and SI would be more appealing as SI considered stability and yield simultaneously.

Journal of Experimental Biology and Agricultural Sciences http://www.jebas.org

\subsubsection{Biplot analysis of stability measures}

Biplot graphical analysis considered the loadings of stability measures for evaluated wheat genotypes to better understand the relationships among stability measures. The first two significant 
principal component analysis (PCA) explained $94.2 \%$ of the variation of the simultaneous ranks of genotypes (Table 10). Two distinguished groups of measures seen in graphical representation (Figure 2). Yield clubbed with PRVG \& MHPRVG. AMMI based measures Za, IPCA1, ASV1 ASTAB, IPCA1, ASV, MASV, MASV1, Za along with SI clustered in a separate cluster. Stability measure WAASB was observed as outliers in biplot analysis. The clustering pattern of measures depicted the different behaviour of stability measures WAASB as compared to other measures.

\subsubsection{Association analysis of stability measures}

The average yield of genotypes had positive values of higher magnitude with SI, MHPRVG, and PRVG values (Table 12). Moreover, other stability measures had expressed only negative values of correlations. MHPRVG and PRVG measures showed similar indirect relations with other stability measures. Values of SI measure had expressed positive correlation of high magnitude with yield, PRVG, and MHPRVG whereas indirect relations of high
Table 10: Loadings of stability measures as per first two PC's (2019-20)

\section{Measure $\mathrm{PC} 1 \quad \mathrm{PC} 2$}

$\begin{array}{lll}\text { IPCA1 } & 0.250 & -0.142\end{array}$

$\begin{array}{lll}\text { MASV1 } & 0.288 & -0.016\end{array}$

$\begin{array}{lll}\text { MASV } & 0.288 & -0.001\end{array}$

$\begin{array}{lll}\text { ASV1 } & 0.277 \quad-0.110\end{array}$

$\begin{array}{lll}\text { ASV } & 0.279 & -0.070\end{array}$

$\begin{array}{lll}\mathrm{Za} & 0.287 & -0.122\end{array}$

\begin{tabular}{lll} 
EV & 0.285 & -0.054 \\
\hline
\end{tabular}

$\begin{array}{lll}\text { SIPC } & 0.283 & -0.048\end{array}$

$\begin{array}{lll}\text { ASTAB } & 0.288 & -0.046\end{array}$

\begin{tabular}{lll}
\hline WAASB & 0.181 & -0.622 \\
\hline
\end{tabular}

\begin{tabular}{|ccc|}
\hline SI & 0.272 & -0.121 \\
\hline $\begin{array}{c}\text { MHPRV } \\
\text { G }\end{array}$ & 0.250 & 0.406 \\
\hline PRVG & 0.249 & 0.422 \\
\hline Yield & 0.243 & 0.442 \\
\hline $\begin{array}{c}\% \\
\text { variance }\end{array}$ & 83.15 & 11.09 \\
\hline
\end{tabular}

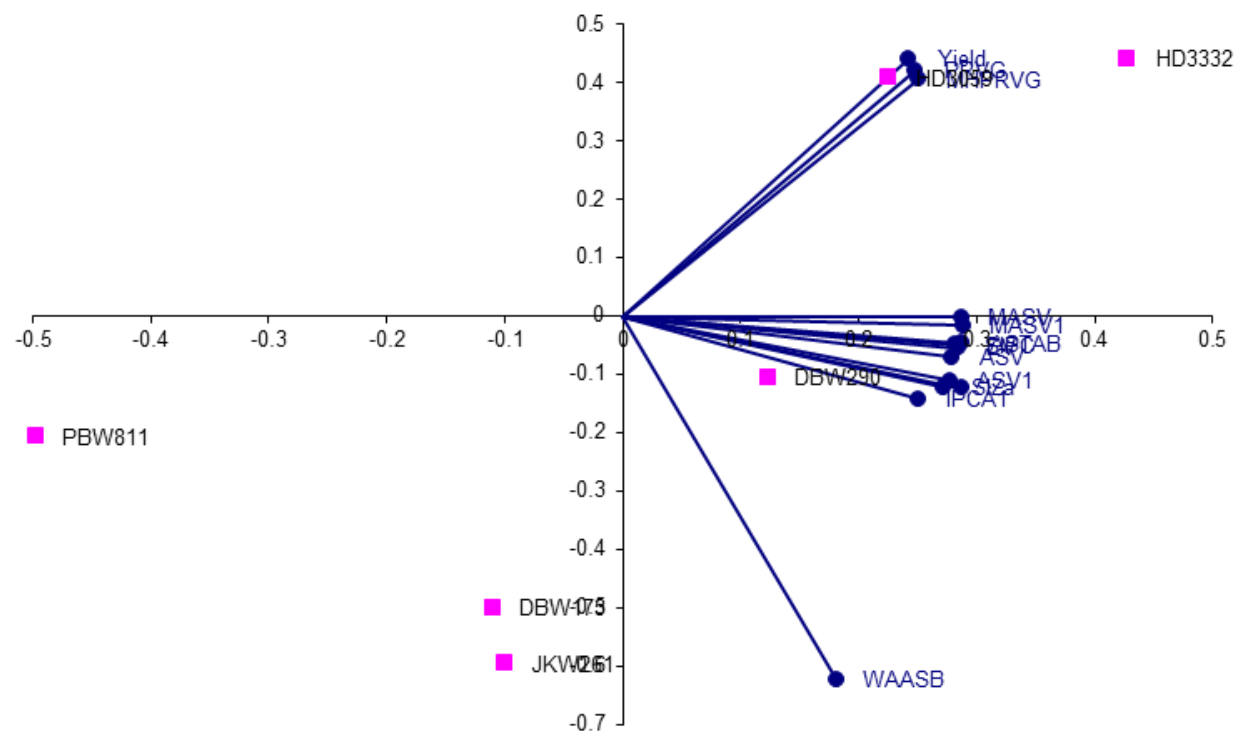

Figure 2: Biplot graphical analysis of stability measures for wheat genotypes evaluated under MET (2019-20)

Table 11: Association analysis of SI with other stability measures (2018-19)

\begin{tabular}{|c|c|c|c|c|c|c|c|c|c|c|c|c|c|}
\hline Measure & MASV1 & MASV & ASV1 & ASV & $\mathrm{Za}$ & $\mathrm{EV}$ & SIPC & ASTAB & WAASB & SI & MHPRVG & PRVG & Yield \\
\hline IPCA1 & 0.880 & 0.563 & 0.967 & 0.883 & 0.926 & -0.373 & -0.067 & 0.759 & 0.970 & -0.884 & -0.776 & -0.760 & -0.757 \\
\hline MASV1 & & 0.882 & 0.932 & 0.927 & 0.878 & -0.139 & -0.057 & 0.945 & 0.913 & -0.953 & -0.899 & -0.883 & -0.889 \\
\hline MASV & & & 0.672 & 0.736 & 0.658 & 0.218 & 0.047 & 0.928 & 0.663 & -0.805 & -0.808 & -0.796 & -0.811 \\
\hline ASV1 & & & & 0.973 & 0.927 & -0.331 & -0.069 & 0.840 & 0.969 & -0.867 & -0.753 & -0.732 & -0.733 \\
\hline ASV & & & & & 0.876 & -0.268 & -0.069 & 0.868 & 0.914 & -0.801 & -0.687 & -0.662 & -0.667 \\
\hline $\mathrm{Za}$ & & & & & & -0.029 & 0.284 & 0.882 & 0.988 & -0.859 & -0.732 & -0.709 & -0.711 \\
\hline EV & & & & & & & 0.786 & 0.171 & -0.163 & 0.141 & 0.128 & 0.133 & 0.116 \\
\hline SIPC & & & & & & & & 0.233 & 0.132 & 0.028 & 0.106 & 0.121 & 0.113 \\
\hline ASTAB & & & & & & & & & 0.868 & -0.876 & -0.811 & -0.791 & -0.802 \\
\hline WAASB & & & & & & & & & & -0.890 & -0.770 & -0.749 & -0.750 \\
\hline SI & & & & & & & & & & & 0.976 & 0.968 & 0.969 \\
\hline MHPRVG & & & & & & & & & & & & 0.999 & 0.999 \\
\hline PRVG & & & & & & & & & & & & & 1.000 \\
\hline
\end{tabular}


Table 12: Association analysis of SI with other stability measures (2019-20)

\begin{tabular}{|c|c|c|c|c|c|c|c|c|c|c|c|c|c|}
\hline Measure & MASV1 & MASV & ASV1 & ASV & $\mathrm{Za}$ & EV & SIPC & ASTAB & WAASB & SI & MHPRVG & PRVG & Yield \\
\hline IPCA1 & 0.714 & 0.651 & 0.946 & 0.888 & 0.885 & 0.736 & 0.716 & 0.774 & 0.893 & -0.692 & -0.491 & -0.436 & -0.429 \\
\hline MASV1 & & 0.989 & 0.836 & 0.866 & 0.937 & 0.973 & 0.967 & 0.972 & 0.931 & -0.769 & -0.559 & -0.509 & -0.512 \\
\hline MASV & & & 0.778 & 0.810 & 0.905 & 0.974 & 0.970 & 0.967 & 0.899 & -0.724 & -0.513 & -0.464 & -0.469 \\
\hline ASV1 & & & & 0.988 & 0.946 & 0.833 & 0.820 & 0.869 & 0.950 & -0.791 & -0.593 & -0.538 & -0.533 \\
\hline ASV & & & & & 0.944 & 0.847 & 0.841 & 0.882 & 0.946 & -0.806 & -0.614 & -0.561 & -0.556 \\
\hline $\mathrm{Za}$ & & & & & & 0.936 & 0.950 & 0.955 & 1.000 & -0.791 & -0.561 & -0.503 & -0.503 \\
\hline EV & & & & & & & 0.974 & 0.996 & 0.932 & -0.775 & -0.570 & -0.518 & -0.522 \\
\hline SIPC & & & & & & & & 0.971 & 0.945 & -0.740 & -0.514 & -0.461 & -0.464 \\
\hline ASTAB & & & & & & & & & 0.952 & -0.800 & -0.594 & -0.541 & -0.545 \\
\hline WAASB & & & & & & & & & & -0.792 & -0.561 & -0.504 & -0.503 \\
\hline SI & & & & & & & & & & & 0.949 & 0.926 & 0.926 \\
\hline MHPRVG & & & & & & & & & & & & 0.997 & 0.996 \\
\hline PRVG & & & & & & & & & & & & & 0.999 \\
\hline
\end{tabular}

degree with AMMI based stability measures. Values of WAASB

measure had positive relations with AMMI based stability measures along with negative values of correlation with SI, yield, PRVG, and MHPRVG. All AMMI based stability measures, ASTAB, SIPC, EV, $\mathrm{Za}$, ASV, ASV1, MASV, MASV1 exhibited positive direct correlation among themselves and with others. Also negative correlation with SI, MHPRVG, PRVG, and yield maintained by AMMI based measures. AMMI based measures did not consider yield and stability simultaneous that is why the selection of genotypes as per SI would not match with wheat genotypes identified by measures.

\section{Conclusions}

Simultaneous consideration of AMMI based stability measures along with yield has been proved quite useful for wheat genotypes evaluated under multi environment trials in the North Western plains Zone of the country. Superiority index exhibited a positive correlation with yield and yield based measures PRVG \& MHPRVG stability measures. Moreover reverse type of relationships maintained by WAASB measure.

\section{Acknowledgements}

The wheat genotypes were evaluated at research fields at coordinated centres of AICW\&BIP across the country. First author sincerely acknowledge the hard work of all the staff for field evaluation and data recording of wheat genotypes.

\section{Conflict Of Interest}

Authors would hereby like to declare that there is no conflict of interests that could possibly arise.

\section{References}

Adjebeng-Danquah J, Manu-Aduening J, Gracen VE, Asante IK, Offei SK(2017) AMMI stability analysis and estimation of genetic parameters for growth and yield components in cassava in the forest and guinea savannah ecologies of Ghana. International Journal of Agronomy 2017:1-10.

Ajay BC, Aravind J, Fiyaz RA, Kumar Narendra, LalChuni, Gangadhar K, Kona Praveen, Dagla MC, Bera SK (2019) Rectification of modified AMMI stability value (MASV). Indian Journal of Genetics and Plant Breeding 79(4) 726-731.

Balestre M, Von Pinho RG, Souza JC, Oliveira RL (2009) Genotypic stability and adaptability in tropical maize based on AMMI and GGE biplot analysis. Genetics and Molecular Research 8:1311-1322.

Bocianowski J, Niemann J, Nowosad K(2019) Genotype-by environment interaction for seed quality traits in interspecific crossderived Brassica lines using additive main effects and multiplicative interaction model. Euphytica 215(7):1-13.

Bornhofen E, Benin G, Storck L, Woyann LG, Duarte T, Stoco MG, Marchioro SV(2017) Statistical methods to study adaptability and stability of wheat genotypes. Bragantia 76:1-10. 
Farshadfar E (2008) Incorporation of AMMI stability value and grain yield in a single non-parametric index (GSI) in bread wheat. Pakistan Journal of Biological Sciences 11:1791-1796.

Farshadfar E, Mahmodi N, Yaghotipoor A (2011) AMMI stability value and simultaneous estimation of yield and yield stability in bread wheat (Triticum aestivum L.). Australian Journal of Crop Science 5:1837-1844.

Gauch HG (2013) A simple protocol for AMMI analysis of yield trials. Crop Science 53:1860-1869.

Kang MS (1993) Simultaneous selection for yield and stability in crop performance trials: Consequences for growers. Agronomy Journal 85:754-757.

Olivoto T (2018) WAASB data, Mendeley Data, v2 doi.org/10.17632/2sjz32k3s3.2

Olivoto T (2019) Metan: multi environment trials analysis. R package version 1.1.0. https://github.com/TiagoOlivoto/metan.

Olivoto T, Lucio A Dal'Col, Gonzalez Silva JA da, Marchioro VS (2019) Mean performance and stability in multi-environment trials I: Combining features of AMMI and BLUP techniques. Agronomy Journal 111:1-12.

Oyekunle M, Menkir A, Mani H, Olaoye G, Usman IS, Ado SG (2017) Stability analysis of maize cultivars adapted to tropical environments using AMMI analysis. Cereal Research Communications 45:336-345.

Purchase JL, Hatting H, Deventer CS van (2000) Genotype $\times$ environment interaction of winter wheat (TriticumaestivumL.) in South
Africa: II. Stability analysis of yield performance. South African Journal of Plant and Soil Science 17:101-107.

Rao AR, Prabhakaran VT (2005) Use of AMMI in simultaneous selection of genotypes for yield and stability. Journal of the Indian Society of Agricultural Statistics 59:76-82.

Resende MDV, Duarte JB (2007) Precision and Quality Control in Variety Trials. Pesquisa Agropecuaria Tropical 37: 182-194.

Sneller CH, Norquest L Kilgore, Dombek D (1997) Repeatability of yield stability statistics in soybean. Crop Science 37:383-390.

Veenstra LD, Santantonio N, Jannink JL, Sorrells ME (2019) Influence of genotype and environment on wheat grain fructan content. Crop Science 59:190-198.

Zali H, Farshadfar E, Sabaghpour SH, Karimizadeh R (2012) Evaluation of genotype $\times$ environment interaction in chickpea using measures of stability from AMMI model. Annals of Biological Research 3:3126-3136.

Zhang Z, Lu C, Xiang ZH (1998) Analysis of variety stability based on AMMI model. Acta Agronomica Sinica 24:304-309.

Zobel RW, Wright MJ, Gauch HG (1988) Statistical analysis of yield trial. Agronomy Journal 80:388-393. 